The importance of $\left[{ }^{11} \mathrm{C}\right]$-choline as a PET/CT marker has been extensively described, although its production presents considerable technical difficulties. The main ones are short half-lives and the occurrence of dimethylformamide (DMF) as a residual solvent. While the losses resulting from the radionuclide decay can be minimised by shortening the duration of the process, the best solution for reducing the content of DMF is its elimination from the reaction environment. In the current work two methods are compared for $\left[{ }^{11} \mathrm{C}\right]$-choline synthesis - a green chemistry approach (with ethanol as a green solvent) and a dry synthesis. The results were compared with each other and with those of the method based on DMF. The solid phase synthesis proved to be the most effective in total elimination of DMF, its final release was the highest, and the synthesis time was the shortest. The optimised synthesis led to the formation of the desired radiotracer with a high radiochemical yield $(65 \% \pm 3 \%)$ in a short production time (12 $\mathrm{min}$ ) and the residual precursor in the final product at the level of $1 \mu \mathrm{g} / \mathrm{ml}$. 27\% increase of the saturation yield was possible, which resulted in $9 \mathrm{GBq}$ higher activity from 40 minutes of beaming. Each test batch passed all standard quality control requirements, and the levels of residual DMEA were below the limits that have been published in the last Pharmacopoeia monograph.

Key words: PET chemistry, carbon-11, SPE, ${ }^{11}$ C-choline, cyclotron, DMF, dimethylformamide, European Pharmacopoeia.

Contemp Oncol (Pozn) 2018; 22 (4): 260-265 DOI: https://doi.org/10.5114/wo.2018.81751

\section{Optimisation of $\left[{ }^{11} \mathrm{C}\right]$-choline synthesis}

\author{
Marcin Szydło ${ }^{1}$, Agnieszka Chmura ${ }^{1}$, Tomasz Kowalski ${ }^{1}$, Mateusz Pocięgiel ${ }^{1}$, \\ Andrea d'Amico' ${ }^{1}$, Maria Sokót²
}

${ }^{1}$ PET Diagnostics Department, Maria Sklodowska-Curie Memorial Cancer Centre and Institute of Oncology, Gliwice Branch, Poland

${ }^{2}$ Department of Medical Physics, Maria Sklodowska-Curie Memorial Cancer Centre and Institute of Oncology, Gliwice Branch, Poland

\section{Introduction}

Cyclotrons are the most commonly used device for positron-emission isotope production by charged particle-induced nuclear reactions. The radioisotope production for diagnostic imaging purposes like ${ }^{11} \mathrm{C},{ }^{13} \mathrm{~N},{ }^{15} \mathrm{O}$, and ${ }^{18} \mathrm{~F}$, is commonly achieved in hospital-based cyclotrons. The principal advantage of such an approach is the high specific activities (SA) that can be obtained through the $(p, x n)$ and $(p, \alpha)$ reactions resulting in the product being a different element from the target [1].

Carbon-11 is particularly suited for labelling compounds with short biological half-lives. It is a positron-emitting radionuclide with a half-life of 20.3 min, which finds widespread use as a tracer in PET. Because carbon atoms are the basic element for biomolecules, a large amount of carbon-11 labelled compounds are currently synthesised and used in diagnostics to investigate different metabolic pathways reflecting the heterogeneity of the malignant tumours. In fact, easy-to-introduce carbon substituents are present in the majority of drugs and bioactive compounds.

$\left[{ }^{11} \mathrm{C}\right]$-choline is a tracer applied for PET/CT imaging of prostate cancer [3] and brain tumours [4], given that the cancer cells, which rapidly proliferate, are characterised by a greater uptake of choline, a constituent of membrane phospholipids [5].

Due the short half-life of carbon-11 and relatively low yield of the production process, the $\left.{ }^{[1} \mathrm{C}\right]$-choline production is limited to centres equipped with a cyclotron. The radiosynthesis process, including purification, formulation, and quality control, should generally not exceed three half-lives of the radionuclide and can be fulfilled even for the short-lived PET radionuclides (halflives from less than a few hours to a few days). There are definite advantages in using short-lived radionuclides, such as a low radiation dose associated with each study, the possibility of serial studies, sometimes on the same day for tracers such as carbon-11, and minimising or even eliminating the risks associated with radioactive waste [1]. On the other hand, for very short-lived radionuclides an in-site chemical lab is necessary. Clinical use of these radionuclides requires extensive validation, and strict operational conditions are essential as well as strict control of product quality before its application. Any subsequent change in the synthesis conditions should be re-validated.

Previously [6] a safe and reliable method for preparing $\left[{ }^{11} \mathrm{C}\right]$-choline and a description of the quality assurance procedures was presented. This process of synthesis fulfils the Guidelines on Good Radiopharmacy Practice issued by the Radiopharmacy Committee of the European Association of Nuclear Medicine (EANM) [7], but also presents some weaknesses. First of all, the actual yield of the synthesis product is only about $20 \%$. Another disadvantage is the solvent used - dimethylformamide (DMF), being a Class 2 solvent. Its average content $(740 \mu \mathrm{g} / \mathrm{ml})$ in the final product is far below the limit imposed by the European Pharmacopoeia $(880 \mu \mathrm{g} / \mathrm{ml})$ [8], but according to the recommendations of the International Council for Harmonisation 
of Technical Requirements for Pharmaceuticals for Human Use (ICH), Class 2 solvents should be limited due to their potential toxicity [9].

The main aim of this work was to modify the procedure in such way as to eliminate DMF from the final product as well as to increase the efficiency of the final product activity and its yield. Two different approaches were tested: the $\left[{ }^{11} \mathrm{C}\right]$-choline synthesis with green chemistry approach (with ethanol as a green solvent) [10] and a dry synthesis. The results were compared with those reported for DMFbased methods [6].

\section{Material and methods}

\section{Materials}

The chemicals were purchased from ABX Advanced Biochemical Compound and the solvents from Avantor Performance Materials Poland. The substrates were used without further purification. Target gas mixture $\left(\mathrm{N}_{2}+0.5 \% \mathrm{O}_{2}\right)$ was purchased from Linde.

For preparation of $\left[{ }^{11} \mathrm{C}\right]$-choline, Sep-Pak Plus Accell CM cation-exchange cartridge and Oasis HLB Plus Short reverse phase cartridge were purchased from Waters and used, as received, without any preconditioning.

To assure sterility of the final product a MILLEX-GS 0.22 $\mu \mathrm{m}$ filter unit was used.

\section{Instrumentation}

The radioactivity of the $\left[{ }^{11} \mathrm{C}\right]$-choline tracer and carbon-11 half-life was measured using a dose calibrator ISOMED 1010.

The HPLC analysis of chemical and radiochemical purity was done using an Acclaim Trinity HPLC column from Thermo Fisher Scientific. The HPLC system (DIONEX Ultimate 3000) was equipped with a UV-VIS DAD, scintillation detector (Bioscan Flow-Count), and Corona CAD (ESA). Three mobile phases were used: $200 \mathrm{mM}$ of ammonium acetate $(\mathrm{pH}=4)(A)$, distilled water (B), and acetonitrile (C) with gradients of $5 \%(A), 35 \%(B)$, and $60 \%$ (C) (gradient time from 0 to $10 \mathrm{~min}$ ), and of $40 \%$ (B) and $60 \%$ (C) (gradient time from 10 to $25 \mathrm{~min}$ ), with a flow rate of $0.7 \mathrm{ml} / \mathrm{min}$.

Gamma radiation energy was measured with Raytest MUCHA multichannel analyser.

Bacterial endotoxin test was performed using Endosafe -PTS apparatus (Charles River).

Radionuclide purity was checked using a CanberraPackard gamma spectrometer with a High-Purity Germanium (HPGe) detector. The spectra were acquired one day after synthesis, and the spectrum acquisition time was three hours.

The concentrations of dimethylaminoethanol (DMAE) and the residual solvents (ethanol and DMF) were determined using an Agilent 6850 gas chromatography system equipped with an autosampler and a flame ionisation detector (split ratio 5.0:1 at a total flow $16 \mathrm{ml} / \mathrm{min}$ with helium as a carrier). An HP-Innowax column (30 m × $0.32 \mathrm{~mm}$ with $0.50 \mu \mathrm{m}$ polyethylene glycol film) was used.

The final product quality control procedures were performed according to the methodology described in previ- ous work [6]. Sterility testing was carried out by a certified laboratory.

\section{Isotope production}

The general procedures of $\left[{ }^{11} \mathrm{C}\right]$-choline production and quality control management are based on the recommendations of Hockley et al. [11] with further modifications [6].

The starting point for the production of the carbon-11 labelled radiopharmaceuticals is the ${ }^{14} \mathrm{~N}(\mathrm{p}, \alpha){ }^{11} \mathrm{C}$ nuclear reaction. The optimum energy for this reaction is between 4 and $20 \mathrm{MeV}$, whereas the cross-section falls beyond about $15 \mathrm{MeV}[12,13]$.

The reaction takes place in the gaseous target of the IBA Cyclone 18/9 cyclotron with a fixed energy of $18 \mathrm{MeV}$ for protons and $9 \mathrm{MeV}$ for deuterons.

A gas target consists of three main parts: collimator, a window holder that holds two foils: titanium and aluminium, and the target body (Fig. 1).

The thickness of the aluminium window is selected to achieve $16 \mathrm{MeV}$ of an effective beam energy on target. The target body is made out of aluminium to reduce activation and radiochemical contamination, and to assure proper cooling.

The radioisotope is produced by irradiation of a gaseous $\mathrm{N}_{2} / \mathrm{O}_{2}$ mixture (the nitrogen target gas containing 0.5\% oxygen) with $16 \mathrm{MeV}$ protons. The target mixture fills an irradiation chamber of approximately $50 \mathrm{~cm}^{3}$.

The filling pressure was 17 bar. The reduction from 20 to 17 bar as compared to the previous technology [6] made it possible to increase the saturation yield from 3.11 to $3.96 \mathrm{GBq} / \mu \mathrm{A}$ ( $27 \%$ increase). Lowering of the filling pressure allows also the target current to be increased to the maximum level provided by the manufacturer, i.e. $40 \mu \mathrm{A}$. The optimisation of these parameters leads to an increase of the in-target activity of $\left[{ }^{11} \mathrm{C}\right]-\mathrm{CO}_{2}$ from $68 \mathrm{GBq}[6]$ to $77 \mathrm{GBq}$ at the same time.

The calculation of the saturation yield takes into account the correction factor accounting for the radionuclide decay during counting and is done according to the equation [14]:

$$
\begin{array}{ll}
Y= & \frac{A}{I\left(1-\operatorname{EXP}\left(\frac{-\ln 2}{t_{1 / 2}{ }^{*} t}\right)\right.} \\
Y & - \text { saturation yield } \\
A & - \text { EOB (end-of-beam) activity } \\
I & - \text { integrated target current } \\
t_{1 / 2} & \text { - half-life of the produced radioisotope } \\
t & \text { - beam time }
\end{array}
$$

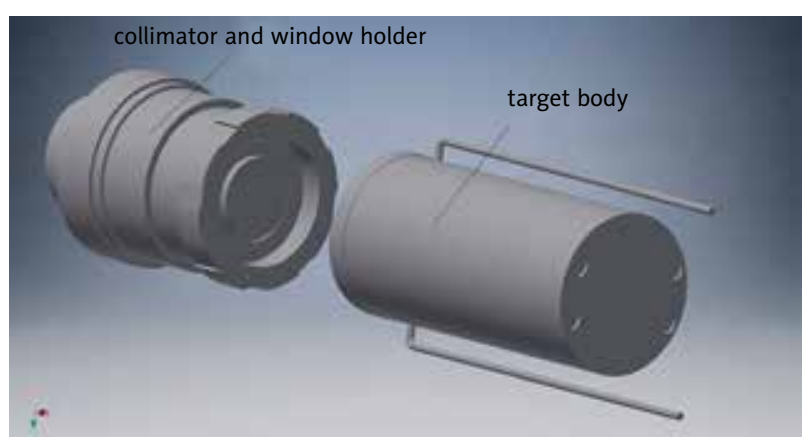

Fig. 1. Gas target main parts: collimator, window holder that holds two foils: titanium and aluminium, and the target body 
The saturation yields were calculated for the activity values obtained at the beam time equal to twice the half-life time of the radionuclide (40 minutes in case of carbon-11).

\section{Synthesis of $\left[{ }^{11} \mathrm{C}\right]$-methyl iodide}

Conversion of the cyclotron-produced $\left[{ }^{11} \mathrm{C}\right]-\mathrm{CO}_{2}$ to $\left.{ }^{[11} \mathrm{C}\right]$-methyl iodide $\left(\left[{ }^{11} \mathrm{C}\right]-\mathrm{Mel}\right)$ and subsequent radiolabelling were performed using an automated Bioscan synthesis module. It consists of a Mel-PLUS ${ }^{\text {TM }}$ unit, adapted for the synthesis of $\left[{ }^{11} \mathrm{C}\right]$-methyl iodide, and a Reform-PLUS ${ }^{\mathrm{TM}}$ unit, where the $\left[{ }^{11} \mathrm{C}\right]$-Mel precursor's synthesis, isolation, purification, and the final product collection take place. The units are installed in the hot cells to decrease the operator's exposure to ionising radiation.

In the first stage of the process, $\left[{ }^{11} \mathrm{C}\right]-\mathrm{CO}_{2}$ is trapped on the molecular sieves of the synthesis module (after its conditioning). A molecular sieve is a material that adsorbs carbon dioxide at room temperatures and releases it when heated to high temperatures. Its conditioning involves removing stable $\mathrm{CO}_{2}$, which is critical for specific activity, and moisture from the filling volume by heating it to $250^{\circ} \mathrm{C}$ and simultaneous purging with nitrogen gas at flow of $15 \mathrm{ml} / \mathrm{min}$.

The radiolabelling and preparation of $\left[{ }^{11} \mathrm{C}\right]$-choline is done in the Bioscan synthesis module. Because carbon-11 is produced in the form of a gaseous $\left[{ }^{11} \mathrm{C}\right]$-carbon dioxide, the chamber is adapted to collect potentially radioactive air from inside of the chambers.

The release of $\left[{ }^{11} \mathrm{C}\right]-\mathrm{CO}_{2}$ into the reaction vial is performed in the same way as the conditioning and lasts for 90 seconds. Using a vial, $\left[{ }^{11} \mathrm{C}\right]-\mathrm{CO}_{2}$ is reduced to $\left[{ }^{11} \mathrm{C}\right]$-methanol $\left(\left[{ }^{11} \mathrm{C}\right]-\mathrm{MeOH}\right)$ with lithium aluminium hydride $\left(\mathrm{LiAlH}_{4}\right)$ in a tetrahydrofuran (THF) environment. After the evaporation of THF from the reaction mixture, a $57 \%$ solution of hydroiodic acid is added to the reaction vial, which reacts with $\left[{ }^{11} \mathrm{C}\right]-\mathrm{MeOH}$ and forms $\left[{ }^{11} \mathrm{C}\right]-\mathrm{Mel}[15]$. The changes of radioactivity and oven temperature taking place during the subsequent stages of the $\left[{ }^{11} \mathrm{C}\right]-\mathrm{Mel}$ synthesis are shown in Figure 2.

\section{$\left[{ }^{11} \mathrm{C}\right]-\mathrm{CH}_{3} \mathrm{I}$ distillation and its reaction with the precursor}

The reaction of $\left[{ }^{11} \mathrm{C}\right]-\mathrm{Mel}$ with DMAE takes place instantaneously at room temperature according to the formula [16]:

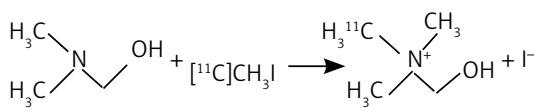

Competitive reactions with water, saline, or ethanol may take place because methyl iodide is highly reactive. Such reactions are possible, if the mentioned reagents infiltrate the ReFORM PLUS ${ }^{\mathrm{TM}}$ tubing assembly. To prevent the competitive reactions, it is important to set up the ReFORM PLUS ${ }^{\text {TM }}$ kit carefully, making sure that the valves are closed. The reagents can be loaded after a double check of the valves.

In a previous study [6] [ $\left.{ }^{11} \mathrm{C}\right]$-methyl iodide distilled from the Mel PLUS ${ }^{\mathrm{TM}}$ unit was transported by a constant flow of nitrogen $(10 \mathrm{ml} / \mathrm{min}$ ) into the vial (a part of the ReFORM PLUS ${ }^{\mathrm{TM}}$ kit) containing the precursor, DMAE, dissolved in DMF in the ratio of $10 \mu \mathrm{l}$ DMAE : $200 \mu \mathrm{l}$ DMF. This method allowed $\left[{ }^{11} \mathrm{C}\right]$-choline to be obtained with a yield of $20 \%$.

In the green chemistry approach, in order to eliminate DMF from the procedure, ethanol was applied as a DMAE solvent. According to $\mathrm{ICH}$ and European Pharmacopoeia,
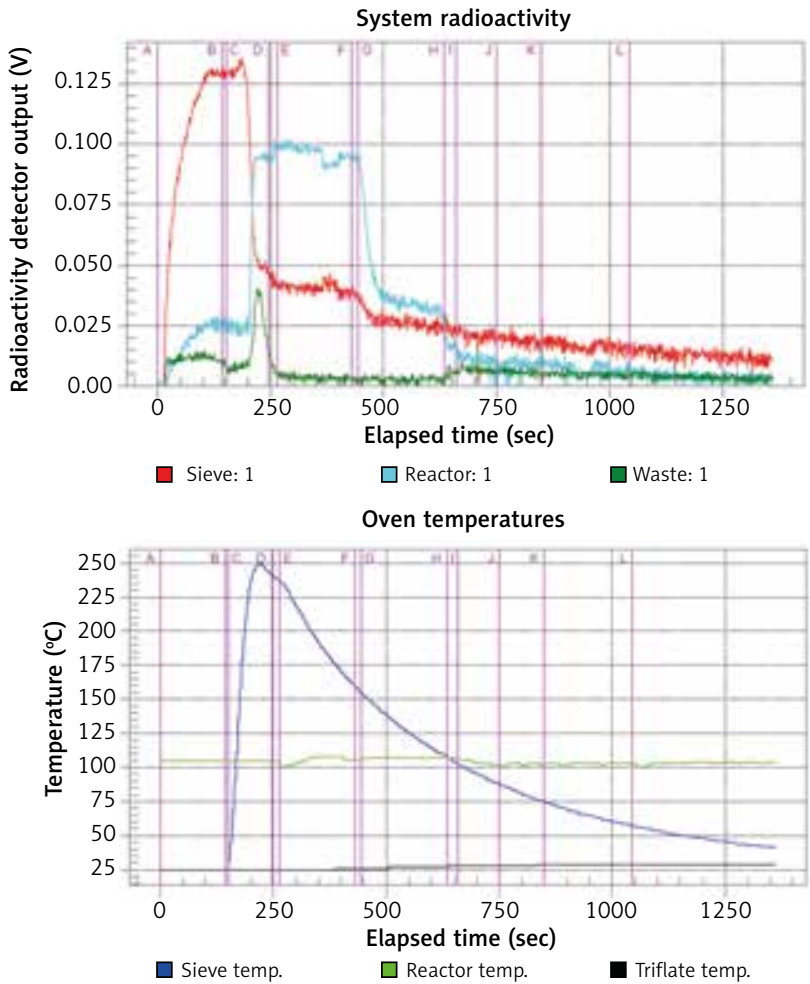

Fig. 2. System radioactivity (upper) and oven temperatures (lower) at the subsequent stages of the $\left[{ }^{11} \mathrm{C}\right]-$ Mel synthesis 
ethanol is a Class 3 solvent. Class 3 solvents are less toxic than Class 2 ones (which should be, however, limited in pharmaceutical products because of their inherent toxicity), and their risk to human health is low when used at levels normally accepted in pharmaceuticals [17]. Ethanol is considered as a green solvent - one of the green solvents group derived from renewable resources and biodegradable to innocuous, often a naturally occurring product [18]. DMAE was dissolved in ethanol in the same ratio as in the case of

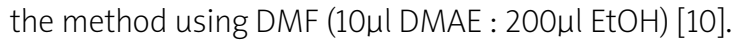

In the second method of synthesis the methylation environment was transferred to the solid phase using the method proposed by Pascali et al. [19]. The experience with [ $\left.{ }^{18} \mathrm{~F}\right]$-fluorocholine $(\mathrm{FCH})$ production with the use of an IBA Synthera ${ }^{\circledR}$ synthesis module [20] proved to be helpful in carrying out this experiment. Thus, the reaction vial was not replaced by a C18 Sep-Pak Light cartridge, but instead an Oasis HLB plus (Waters) SPE cartridge [20]. In order to maximise the reformulation process, the script according to which the module runs the process was modified. The modifications involved changing the valve work sequence so that the paths would lead through the cartridges as well as the optimisation of the times of each step of the script. It resulted in shortening of the production process from 17 to 12 minutes.

The HLB cartridge was connected in series with the SepPak Accell Plus CM (Waters) cartridge preceding it. $0.5 \mathrm{ml}$ of DMAE was added on the HLB cartridge and it was flushed with $30 \mathrm{ml}$ of air in three portions of $10 \mathrm{ml}$ each to remove the excess.

\section{Isolation and purification of $\left[{ }^{11} \mathrm{C}\right]$-choline}

In both methods that use a reaction vial, the isolation and purification process is a four step-procedure conducted by the ReFORM PLUS ${ }^{\mathrm{TM}}$ unit. First, $1 \mathrm{ml}$ of ethanol was added to the reaction vial to homogenise the mixture. Afterward, the whole mixture was extracted to the solid phase on a cation exchange resin (Sep-Pack Accell Plus $\mathrm{CM}$; Waters [6]). As the ionic compound, $\left[{ }^{11} \mathrm{C}\right]$-choline was captured by the SPE column, while the remaining components of the reaction mixture had been removed. To confirm the proper purification of the product, especially from the substances that were insoluble in organic solvents, the SPE column was washed twice with $5 \mathrm{ml}$ of water. The final product was released from the SPE column using $0.9 \%$ saline solution and collected in a sterile, pyrogen-free vial with septum enclosure after the previous filtration on a 0.22- $\mu \mathrm{m}$ membrane sterile filter.

In the case of methylation of DMAE on a solid phase ethanol runs directly through the HLB cartridge removing unreacted DMAE and $\left[{ }^{11} \mathrm{C}\right]$-choline from it. While $\left[{ }^{11} \mathrm{C}\right]$-choline is trapped on the Accel Plus cartridge, DMAE goes to a waste container. In the next step, the product is backflushed from the cartridge with water and released to a product vial using $10 \mathrm{ml}$ of $0.9 \%$ saline in the same way as for both other, DMF based and "green chemistry", methods. The radioactivity changes during the reformulation performed using the SPE method are shown in Figure 3.

\section{Results}

The main adjustments of the parameters of both tested methods (green chemistry and solid phase ones) of the $\left[{ }^{11} \mathrm{C}\right]$-choline production resulting in the highest possible yields and insuring reliability and reproducibility are shown in Table 1 together with the results of the previously used DMF based synthesis, for the sake of comparison.

The continuous detection of radioactivity allows monitoring of the production process on each step (Fig. 2 and 3). In a properly running process an increase of radioactivity is seen on the molecular sieves (trapping of $\left[{ }^{11} \mathrm{C}\right]-\mathrm{CO}_{2}$ in the module). If the molecular sieves are conditioned well and the module works correctly, it is accompanied by the simultaneous decrease of radioactivity on the sieves and an increase on the reactor. During $\left[{ }^{[1} \mathrm{C}\right]-$ Mel distillation, radioactivity leaves the module, and this fact should be observed in the graph. In turn, the waste bottle detector of the Mel+ module should not indicate any significant increase of the background radioactivity from the sieves and reactor (Fig. 2).

The reformulation monitoring in the SPE method is presented in Figure 3. During the whole process a slight decrease of radioactivity may appear due to decay and removal of unreacted $\left[{ }^{11} \mathrm{C}\right]-$ Mel during purification. A rapid radioactivity decrease is observed when $\left[{ }^{11} \mathrm{C}\right]$-choline is released to the vial (Fig. 3). Loss of radioactivity on purification or even $\left[{ }^{11} \mathrm{C}\right]$-Mel transfer step may be caused by contamination on the ReFORM Plus ${ }^{\mathrm{TM}}$ tubing or its leaks.

The differences between the "wet" synthesis with the precursor dissolved in DMF and EtOH, and the "dry" synthesis with the precursor embedded on the HLB cartridge are

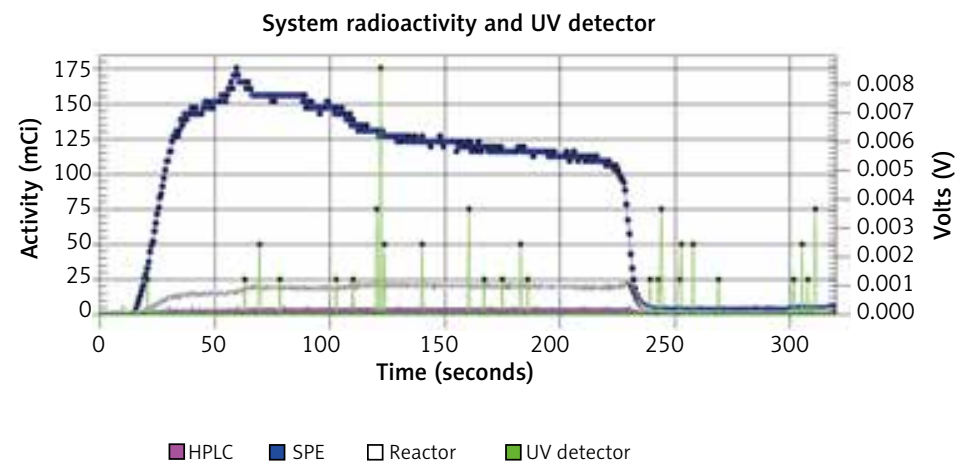

Fig. 3. Online radioactivity detection in the solid phase extraction (SPE) method 
Table 1. The optimal parameters for $\left.{ }^{[1} \mathrm{C}\right]$-choline production

\begin{tabular}{|c|c|c|c|}
\hline Parameter & Green chemistry EtOH method & Solid phase method & DMF method [6] \\
\hline Target filling pressure & 17 bar & 17 bar & 20 bar \\
\hline Target current & $40 \mu \mathrm{A}$ & $40 \mu \mathrm{A}$ & $30 \mu \mathrm{A}$ \\
\hline Saturation yield & $3.96 \mathrm{GBq} / \mu \mathrm{A}$ & $3.96 \mathrm{GBq} / \mu \mathrm{A}$ & $3.11 \mathrm{GBq} / \mu \mathrm{A}$ \\
\hline Amount of DMF & Not used & Not used & $200 \mu \mathrm{l}$ per run \\
\hline Amount of DMAE & $10 \mu \mathrm{l}$ (dissolved in EtOH) & $\begin{array}{c}\text { Up to } 500 \mu \mathrm{l} \text { (embedded on HLB } \\
\text { cartridge) }\end{array}$ & $10 \mu \mathrm{l}$ (dissolved in DMF) \\
\hline Time of reformulation & $17 \mathrm{~min}$ & $12 \mathrm{~min}$ & $17 \min$ \\
\hline
\end{tabular}

DMF-dimethylformamide; DMAE - dimethylaminoethanol

Table 2. Comparison of yield values, unreacted precursor, and residual solvent concentrations in $\left[{ }^{11} \mathrm{C}\right]$-choline obtained by each method

$\begin{array}{lccc}\text { Parameter } & \text { DMF method } & \text { Ethanol method } & \text { Solid-phase method } \\ \text { Yield (total) } & 23 \% & 9 \% & 68 \% \\ \text { DMAE } & 36.1 \mu \mathrm{g} / \mathrm{ml} & 20.2 \mu \mathrm{g} / \mathrm{ml} & 70.1 \mathrm{\mu g} / \mathrm{ml} \\ \text { Ethanol } & 2.93 \mathrm{mg} / \mathrm{ml} & 2.24 \mathrm{mg} / \mathrm{ml} & 0.58 \mathrm{mg} / \mathrm{ml} \\ \text { DMF } & 0.74 \mathrm{mg} / \mathrm{ml} & - & - \\ \text { DMF- dimethylformamide; DMAE - dimethylaminoethanol } & & \end{array}$

DMF-dimethylformamide; DMAE - dimethylaminoethanol

shown in Table 2. Besides the synthesis yields, they involve also the chemical purity (a lack of DMF) and the changes in the DMAE and ethanol concentrations. A significant difference in ethanol concentration between "wet" and "dry" synthesis is observed, which is due to changes in script. The time of ethanol delivery was extended from 50 seconds to 75 seconds, which enabled its more accurate removal. Extension of the "ethanol step" with parallel shortening of the script duration was possible thanks to shortening the time of the other steps, such as rinsing the cartridge with two portions of $5 \mathrm{ml}$ of water in place of one portion of $10 \mathrm{ml}$. Two portions of lower volume result in lower backpressure on the tubing, which gives a faster flow.

Each test batch was controlled with the use of the quality-control procedures described herein [6]. The radiochemical purity (radio-HPLC), radionuclide purity (half-life measurement, gamma-ray identification, and HPGe spectroscopy), and microbiological purity (endotoxin and sterility test) were repeatable and similar between the methods [6].

\section{Discussion}

The main aim of this work was to optimise the $\left[{ }^{11} \mathrm{C}\right]$-choline synthesis process, in relation to the process described in [6], by increasing the final synthesis yield while minimising or even completely eliminating DMF.

Two approaches to the $\left[{ }^{11} \mathrm{C}\right]$-choline synthesis: the method using a green solvent, ethanol, and a dry synthesis, where DMAE is embedded on the Oasis HLB plus, were applied and the results were compared. They were also compared with results of the synthesis based on the DMAE precursor dissolved in DMF, which were presented in [6]. The solid phase synthesis proved to be the most effective in total elimination of DMF; its final release was the highest, and the synthesis time was the shortest (Table 2). Unfortunately, the content of DMAE precursor in the final product is still high, although it is a non-toxic compound and its concentration remains below the requirements of the European Pharmacopoeia [21].

Using DMF was a pioneering way for the $\left[{ }^{11} \mathrm{C}\right]$-choline synthesis. However, in spite of a reasonable radiotracer yield, the high solvent concentration makes this method unacceptable. Solvent replacement for ethanol makes the product safer for patients, but the radiochemical yield may appear insufficient for manufacturers due to the cost-benefit ratio. Thus, the transfer of a reaction environment to a solid phase appears to be most effective way to increase the number of radiotracer doses per batch, simultaneously making it safer for the patient without serious loss of diagnostic properties. An important novelty is a publication of Pharmacopoeia monography describing $\left[{ }^{18} \mathrm{~F}\right]$-fluorocholine and its impurities assay. Not all of the featured tests are appropriate for use in the $\left[{ }^{11} \mathrm{C}\right]$-choline $\mathrm{QC}$, but DMEA, present in both radiotracers, $\left[{ }^{18} \mathrm{~F}\right]$-fluorocholine, and $\left[{ }^{11} \mathrm{C}\right]$-choline can be assigned according to the procedure described in this Pharmacopoeia monograph [21]. Until the mentioned monograph appeared, the upper limit of DMEA in the final product remained unspecified. Now, it has been determined as $1.0 \mathrm{mg}$ per dose. Thus, when taking into account that a final product vial (FPV) is, in fact, a multidose vial, having at its disposal the maximum possible radioactivity of at least 10 doses, then, after a 10-fold dilution of the FPV the DMAE content in the patient syringe would be not higher than $0.7 \mathrm{mg}$ per dose. Although DMEA is non-toxic and used as a nutrition additive, it may compete with the uptake of $\left.{ }^{[11} \mathrm{C}\right]$-choline into the cell [22]. Shao et al. [23] rejected the use of silica-based hydrophobic SPE cartridge (e.g. C18 and HLB plus) proceeding synthesis on a single cation-exchange cartridge (Sep-Pak CM-Light) explaining it with a lower back-pressure. However, a lower back-pressure could shorten the synthesis time increasing the end of synthesis (EOS) yields, and use of two cartridges in serial should give a higher purification level due to a different sorption mechanism 
resulting, presumably, in a higher chemical and radiochemical purity. Such an idea will be tested in our further studies on $\left[{ }^{11} \mathrm{C}\right]$-choline and $\left[{ }^{18} \mathrm{~F}\right]$-fluorocholine synthesis.

\section{Conclusions}

The results presented above demonstrate that through simple modifications of the synthesis conditions it was possible to produce clinical doses of $\left[{ }^{11} \mathrm{C}\right]$-choline. The solid phase synthesis proved to be the most effective in total elimination of DMF, its final release was the highest, and the synthesis time was the shortest. The synthesis is fully automated and the radiopharmaceutical doses for clinical use meet and exceed established quality control criteria.

The authors declare no conflict of interest.

\section{References}

1. Ruth TJ. The uses of radiotracers in the life sciences. Rep Prog Phys 2009; 72: 1-23.

2. Shields AF, Graham MM, Kozawa SM, et al. Contribution of labeled carbon dioxide to PET imaging of carbon-11-labeled compounds. J Nucl Med 1992; 33: 581-584.

3. Yamaguchi T, Lee J, Uemura H, et al. Prostate cancer: a comparative study of 11C-choline PET and MR imaging combined with proton MR spectroscopy. Eur I Nucl Med Mol Imaging 2005; 32: 742-748.

4. Hara T, Kosaka N, Shinoura N, Kondo T. PET imaging of brain tumor with [methyl- ${ }^{-11}$ C]choline. J Nucl Med 1997; 38: 842-847.

5. de Jong IJ, Pruim J, Elsinga PH, Vaalburg W, Mensink HJ. Preoperative Staging of Pelvic Lymph Nodes in Prostate Cancer by 11C-Choline PET. J Nucl Med 2003; 44: 331-335.

6. Szydło M, Jadwiński M, Chmura A, Gorczewski K, Sokół M. Synthesis, isolation and purification of $\left[{ }^{11} \mathrm{C}\right]$-choline, a PET tracer. Contemp Oncol (Pozn) 2016; 20: 229-236.

7. Guidelines on Current Good Radiopharmacy Practice (cGRPP) in the Preparation of Radiopharmaceuticals. EANM Radiopharmacy Committee, version 2; March 2007.

8. European Pharmacopoeia. $8^{\text {th }}$ edition; chapter 2.4.24. Identification and control of residual solvents.

9. Impurities: Guideline for Residual Solvents $\mathrm{O} 3 \mathrm{C}(\mathrm{R} 6)$. ICH Harmonised Guideline. Current Step 4 version dated October 20, 2016.

10. Shao X, Fawaz MV, Jang K, Scott PJ. Ethanol as a Solvent for Carbon-11 Radiochemistry. In: Radiochemical Syntheses Vol. 2: Further Radiopharmaceuticals for Positron Emission Tomography and New Strategies for Their Production, Scott PJ, Kilbournm MR (eds.). John Wiley \& Sons, 2015; 207-232.

11. Hockley BG, Henderson B, Shao X. Synthesis of $\left.{ }^{11} \mathrm{C}\right]$ Choline Chloride $\left.\left({ }^{11} \mathrm{C}\right] \mathrm{CHL}\right)$. In: Radiochemical Syntheses Vol. 1: Radiopharmaceuticals for Positron Emission Tomography, Scott PJ, Hockley BG (eds.). John Wiley \& Sons, 2012; 169-177.

12. Hara T, Yuasa M. Automated synthesis of $\left[{ }^{11} \mathrm{C}\right]$ choline, a positron-emitting tracer for tumor imaging. Appl Radiat Isot 1999; 50: 531-533.

13. Recommended cross sections for ${ }^{14} \mathrm{~N}(\mathrm{p}, \mathrm{a})^{11} \mathrm{C}$ reaction: https:// www-nds.iaea.org/medical/n4p11c0.html

14. Hoehr C, Oehlke E, Benard F, et al. ${ }^{44} \mathrm{Sc}$ production using a water target on a 13 MeV cyclotron. Nucl Med Biol 2014; 41: 401-406.

15. Marazano C, Maziere M, Berger G, Comar D. Synthesis of methyl iodide- ${ }^{-11} \mathrm{C}$ and formaldehyde ${ }^{-11} \mathrm{C}$. In: Radiompharmaceuticals and Other Compound Labelled with Short-Lived Radionuclides, Welch MJ (ed.). Pergamon Press, 1977; 49-52.

16. Rosen MA, Jones RM, Yano Y, Budinger TF. Carbon-11 Choline: Synthesis, Purification, and Brain Uptake Inhibition by 2-Dimetylaminoethanol. J Nucl Med 1985; 26: 1424-1428.
17. Grodowska K, Parczewski A. Organic solvents in the pharmaceutical industry. Acta Pol Pharm 2010; 67: 3-12.

18. Sherman J, Chin B, Huibers PDT, Garcia-Valls R, Hatton TA. Solvent Replacement for Green Processing. Environ Health Perspect 1998; 106: 253-271.

19. Pascali C, Bogni A, Itawa R, Cambiè M, Bombardieri E. $\left[{ }^{11} \mathrm{C}\right]$ Methylation on a $C_{18}$ Sep-Pak cartridge: a convenient way to produce [N-methyl- ${ }^{-11} \mathrm{C}$ ]choline. J Labelled Comp Radiopharm 2000; 43: 195203.

20. Slaets D, De Bruyne S, Dumolyn C, Moerman L, Mertens K, De Vos F. Reduced Dimethylaminoethanol in $\left[{ }^{18} \mathrm{~F}\right] \mathrm{fluoromethylcholine:} \mathrm{an}$ important step towards enhanced tumor visualization. Eur J Nucl Med Mol Imaging 2010; 37: 2136-2145.

21. European Pharmacopoeia. $8^{\text {th }}$ edition; supplement 8 ; monography 2793. Fluorocholine $\left({ }^{18} \mathrm{~F}\right)$ Injection.

22. Reischl G, Bieg C, Schmiedl O, Solbach C, Machulla HJ. Highly efficient automated synthesis of [11C] choline for multi dose utilization. Appl Radiat Isot 2004; 60: 835-838.

23. Shao X, Hockley BG, Hoareau R, Schnau PL, Scott PJH. Fully automated preparation of $\left[{ }^{[11} \mathrm{C}\right]$ choline and $\left[{ }^{18} \mathrm{~F}\right]$ fluoromethylcholine using TracerLab synthesis modules and facilitated quality control using analytical HPLC. Appl Radiat Isot 2011; 69: 403-409.

\section{Address for correspondence}

\section{Marcin Szydło}

PET Diagnostic Department

Maria Sklodowska-Curie Memorial Cancer Centre

Institute of Oncology

Branch in Gliwice

15 Wybrzeże Armii Krajowej St.

44-101 Gliwice, Poland

e-mail: Marcin.Szydlo@io.gliwice.pl

Submitted: 19.10 .2018

Accepted: $\quad 30.11 .2018$ 